\title{
Real-World Outcome of Platinum-Based Chemotherapy in Advanced Breast Cancer (ABC): A Retrospective Study from a Tertiary Cancer Center in India
}

\author{
Indhuja Muthiah Vaikundaraja1 Manikandan Dhanushkodi ${ }^{1}$ Venkatraman Radhakrishnan ${ }^{10}$ \\ Jayachandran Perumal Kalaiarasi10 Nikita Mehra10 Gangothri Selvarajan ${ }^{1}$ Arun Kumar Rajan ${ }^{1}$ \\ Siva Sree Kesana ${ }^{1}$ Balasubramanian Ananthi ${ }^{2}$ Priya lyer $^{2}$ Manjula Rao ${ }^{3}$ Arvind Krishnamurthy ${ }^{3}$ \\ Sridevi Velusamy ${ }^{3}$ Rama Ranganathan ${ }^{4}$ Tenali Gnana Sagar ${ }^{1}$
}

\footnotetext{
${ }^{1}$ Department of Medical Oncology, Cancer Institute (WIA), Chennai, Tamil Nadu, India

2 Department of Radiation Oncology, Cancer Institute (WIA), Chennai, Tamil Nadu, India

${ }^{3}$ Department of Surgical Oncology, Cancer Institute (WIA), Chennai, Tamil Nadu, India

${ }^{4}$ Department of Epidemiology \& Biostatistics, Cancer Institute (WIA), Chennai, Tamil Nadu, India
}

Address for correspondence Manikandan Dhanushkodi, MD, DM, DNB, Medical Oncology, Cancer Institute (WIA), Chennai, 38, Sardar Patel Road, Chennai, Tamil Nadu, 600036, India (e-mail: dmani1982@gmail.com).

Ind J Med Paediatr Oncol

\section{Abstract \\ Keywords \\ - advanced breast cancer \\ - platinum-based chemotherapy \\ - real-world outcome}

Introduction There is a paucity of data on platinum-based chemotherapy in advanced breast cancer $(A B C)$ from developing countries like India.

Objectives The objectives were to analyze the efficacy and safety of platinum-based chemotherapy in patients with ABC.

Materials and Methods This was a retrospective study of 35 patients with $A B C$ who were treated with platinum-based chemotherapy (gemcitabine and carboplatin, [GC]) in a tertiary cancer center in India from August 2015 to November 2019. The inclusion criteria were patients with $A B C$, who had received palliative chemotherapy with GC. The exclusion criteria were patients who had received less than two cycles of GC and patients who received platinum-based chemotherapy for neuroendocrine carcinoma of the breast.

Results The median age was 45 years (range: $28-68$ years). All patients were female (97\%) except one male (3\%). The histology was ductal carcinoma (77\%), mixed (17\%), and others (6\%). Out of the 12 patients tested for breast cancer (BRCA) gene mutation, six patients had a BRCA mutation. Patients with metastatic and locally progressive disease were 91 and $9 \%$, respectively. The median number of prior lines of systemic therapy for metastatic disease was 1 (range: $0-5$ ). The median number of sites of metastasis was 2 (range: $0-5$ ). Patients with visceral crises were $23 \%$. The median
DOI https://doi.org/ 10.1055/s-0041-1735597. ISSN 0971-5851.
(C) 2021. Indian Society of Medical and Paediatric Oncology. All rights reserved.

This is an open access article published by Thieme under the terms of the Creative Commons Attribution-NonDerivative-NonCommercial-License, permitting copying and reproduction so long as the original work is given appropriate credit. Contents may not be used for commercial purposes, or adapted, remixed, transformed or built upon. (https://creativecommons.org/ licenses/by-nc-nd/4.0/)

Thieme Medical and Scientific Publishers Pvt. Ltd., A-12, 2nd Floor, Sector 2, Noida-201301 UP, India 
number of cycles of GC chemotherapy received was 6 (range: 2-6). A dose reduction in chemotherapy was done in $74 \%$. The responses among 34 evaluable patients were complete response (11\%), partial response (24\%), stable disease ( $41 \%)$, and progressive disease (24\%). Grade 3 or more hematological and nonhematological toxicities were observed in 69 and $9 \%$, respectively. The median progression-free survival and overall survival were 6 and 8 months, respectively. The 1-year progression-free survival and overall survival were 19 and $34 \%$, respectively. Multivariate analysis showed that patients who had received more than 3 cycles had a better outcome.

Conclusion GC was an active and well-tolerated regimen in $A B C$ regardless of the receptor status. Further prospective randomized studies are warranted to assess the optimal regimen in patients with triple-negative breast cancer.

\section{Introduction}

Platinum-based neoadjuvant chemotherapy (cisplatin and carboplatin) has been shown to improve pathological complete response in triple-negative breast cancer (TNBC), especially in the breast cancer (BRCA) mutant subtype. ${ }^{1}$ Platinum-based chemotherapy (PBC) can be combined with anti-HER2 therapy (trastuzumab) for the treatment of HER2-positive BRCA. ${ }^{2}$ The impact of $\mathrm{PBC}$ as compared to non$\mathrm{PBC}$ in advanced breast cancer $(\mathrm{ABC})$ is unclear. The chemotherapy drugs that can be combined with platinum include taxane, vinorelbine, etoposide, and gemcitabine. ${ }^{3}$ The response rates are higher in the first line as compared to second or third-line therapy. ${ }^{4}$ There is a paucity of data on $\mathrm{PBC}$ in $\mathrm{ABC}$ from developing countries like India. The objectives of this study were to analyze the efficacy and safety of $P B C$ in patients with $A B C$.

\section{Materials and Methods}

This was a retrospective study of 35 patients with $A B C$ who had received palliative chemotherapy with gemcitabine and carboplatin (GC) in a tertiary care cancer center from August 2015 to November 2019. The data were retrieved from the electronic medical records (EMR) of these patients for whom gemcitabine and carboplatin prescription was given. At our hospital, patient records registered from 1954 until 2016, and records of patients who had deceased were scanned. The data of patients for whom case records were scanned were obtained from the EMR. For the alive patients registered after 2016, we obtained data from the individual case record obtained from the tumor registry.

The inclusion criteria were patients with $A B C$, who had received palliative chemotherapy with GC. The exclusion criteria were patients who had received less than two cycles of GC and patients who received $\mathrm{PBC}$ for neuroendocrine carcinoma of the breast. BRCA was tested as per National Comprehensive Cancer Network (NCCN) hereditary BRCA testing criteria ${ }^{5}$ and the methodology used was Ion Torrent next-generation sequencing. The primary objective was to assess the progression-free survival (PFS) and overall survival (OS) of patients with recurrent/metastatic BRCA who received palliative che- motherapy with GC while the secondary objective was to assess the toxicity.

Prechemotherapy blood investigations included hemogram, renal function test, and liver function test before the day (D) 1 of each cycle and hemogram and differential count before D8 of each cycle. Chemotherapy was initiated only if the absolute neutrophil count was more than $1000 / \mu \mathrm{L}$ and platelet count was $>1$ lakh/ $/ \mu \mathrm{L}$. The premedications were injection palonosetron $0.25 \mathrm{mg}$ intravenous bolus and injection dexamethasone $12 \mathrm{mg}$ intravenous bolus 30 minutes before chemotherapy. The chemotherapy schedule was injection gemcitabine 1 $\mathrm{gm} / \mathrm{m}^{2}$ in $250 \mathrm{~mL} 0.9 \%$ normal saline over 30 minutes intravenously on D1 and D8 and injection carboplatin area under the curve 5 or 6 in $250 \mathrm{~mL} 0.9 \%$ normal saline over 1 hour on D1.

Patients were assessed clinically for response and toxicity before each cycle. Imaging was done with either chest X-ray, ultrasound of abdomen/pelvis, or contrast-enhanced chest tomography of chest/abdomen/pelvis or positron imaging tomography-computed tomography once every 3 to 4 months and when clinically indicated. Responses were assessed as per the Response Evaluation Criteria in Solid Tumors, version 1.1 criteria. ${ }^{6}$ Toxicity was graded as per Common Terminology Criteria for Adverse Events, version 4.0. ${ }^{7}$ Chemotherapy dose reduction was done in patients with $\geq$ grade 3 toxicity and discontinued in patients with life-threatening toxicity.

\section{Statistical Analysis}

Descriptive statistics were used to analyze the baseline characteristics. PFS was calculated from the date of initiation of GC to the date of recurrence or death. OS was calculated from the date of the initiation of GC to the date of death due to any cause. Survival was estimated by the Kaplan-Meier method and compared across groups using the log-rank test. Cox proportional hazard model was used to find the prognostic factors affecting the outcome. All $p$-values were two-sided, and values $<0.05$ were considered significant. This was performed using the Statistical Package for the Social Sciences version 15 (SPSS), Chicago, Illinois, United States. 
Ethics

The procedures followed were in accordance with the ethical standards of the responsible committee on human experimentation and with the Helsinki Declaration of 1964, as revised in 2013. The study was approved by the Institutional Ethics Committee of Cancer Institute (WIA), Chennai (IEC/ 2020/Aug 08), dated Aug 14, 2020 and a waiver of consent was obtained as this was a retrospective study.

\section{Results}

\section{Baseline Characteristics}

A total of 35 patients were included in this analysis with a median follow-up of 8 months (range: 2-39 months). The median duration from diagnosis to start of GC chemotherapy was 18 months (range: $2-113$ months). The median age was 45 years (range: 28-68 years). All patients were females ( $n=34 / 35,97 \%)$ except for one male $(n=1 / 35,3 \%)$. Premenopausal women were $76 \%(n=26 / 35)$ and the rest $24 \%$ $(n=8 / 35)$ were postmenopausal. The Eastern Cooperative Oncology Group Performance Status (ECOG PS) was 1 (83\%) and 2 (17\%). The histology was ductal carcinoma (77\%), mixed (17\%), and others (6\%). The differentiation was grade $2(17 \%)$ and grade $3(80 \%)$. The molecular subtype was luminal B ( $n=10 / 35,29 \%)$, HER2 positive ( $n=6 / 35,17 \%)$, and triple-negative subtype $(n=19 / 35,54 \%)$. Two of the six patients with HER2-positive BRCA had received adjuvant trastuzumab. Out of the 12 patients tested for BRCA 1 and 2 gene mutations, six patients had a BRCA 1 mutation. Recurrence was confirmed by biopsy in $37 \%(n=13 / 35)$ patients. Patients with metastatic and locally progressive disease were 91 and $9 \%$, respectively. The median number of prior lines of systemic therapy for metastatic disease was 1 (range: 0-5). The median number of sites of metastasis was 2 (range: 0-5). Patients with visceral crises were 23\% $(n=8 / 35)$. This study included two patients with brain metastasis and one with choroidal metastasis. The baseline characteristics are shown in - Table $\mathbf{1}$.

\section{Treatment, Response, and Toxicity}

The median number of cycles of GC chemotherapy received was 6 (range: 2-6). A dose reduction in chemotherapy was done in $74 \%(n=26 / 35)$. The responses were complete response $(n=4 / 35,11 \%)$, partial response $(n=8 / 35,23 \%)$, stable disease $(n=14 / 35,40 \%)$, progressive disease $(n=8 / 35$, $23 \%)$, and unknown $(n=1 / 35,3 \%)$. The hematological and nonhematological toxicities of $\geq$ grade 3 were observed in 69 and $9 \%$, respectively. Grade 3 or more anemia, leucopenia, and thrombocytopenia were observed in 34,46 , and $37 \%$, respectively. Febrile neutropenia was observed in $9 \%$ of patients. Grade 3 or more chemotherapy-induced nausea and vomiting, hypersensitivity, and neuropathy were observed in 3, 3, and 3\%, respectively. There was no treatmentrelated mortality.

\section{Survival}

The median PFS (-Fig. 1) and OS (-Fig. 2) were $6(95 \%$ confidence interval $[\mathrm{CI}]$ : 3.2-5.7 months) and 8 months (95\%
Table 1 Baseline characteristics $(n=35)$

\begin{tabular}{|c|c|}
\hline Variable & Number (\%) \\
\hline Median age & $\begin{array}{l}45 \text { years (range: } \\
28-68 \text { years) }\end{array}$ \\
\hline \multicolumn{2}{|l|}{ Sex } \\
\hline Female & $34(97)$ \\
\hline Male & $1(3)$ \\
\hline \multicolumn{2}{|l|}{ Menopausal status $^{\mathrm{a}}$} \\
\hline Premenopausal & $26(76)$ \\
\hline Postmenopausal & $8(24)$ \\
\hline \multicolumn{2}{|l|}{ Comorbid illness $^{b}$} \\
\hline Diabetes mellitus & $9(27)$ \\
\hline Hypertension & $7(21)$ \\
\hline Others & $8(24)$ \\
\hline None & $18(54)$ \\
\hline \multicolumn{2}{|l|}{ ECOG performance status } \\
\hline 0 & $0(0)$ \\
\hline 1 & $29(83)$ \\
\hline 2 & $6(17)$ \\
\hline 3 or 4 & $0(0)$ \\
\hline \multicolumn{2}{|l|}{ Histology } \\
\hline Infiltrating ductal carcinoma & $27(77)$ \\
\hline Mixed & $6(17)$ \\
\hline Others $^{c}$ & $2(6)$ \\
\hline \multicolumn{2}{|l|}{ Differentiation } \\
\hline Grade 1 & $0(0)$ \\
\hline Grade 2 & $6(17)$ \\
\hline Grade 3 & $28(80)$ \\
\hline Unknown & $1(3)$ \\
\hline \multicolumn{2}{|l|}{ Estrogen receptor } \\
\hline Positive & $13(37)$ \\
\hline Negative & $22(63)$ \\
\hline \multicolumn{2}{|l|}{ Progesterone receptor } \\
\hline Positive & $8(23)$ \\
\hline Negative & $27(77)$ \\
\hline \multicolumn{2}{|l|}{ HER2 } \\
\hline Positive & $6(17)$ \\
\hline Negative & $28(80)$ \\
\hline Unknown & $1(3)$ \\
\hline \multicolumn{2}{|l|}{ Molecular subtype } \\
\hline $\begin{array}{l}\text { Luminal A (ER/PR positive, HER2 } \\
\text { negative \& Ki } 67 \leq 20 \% \text { ) }\end{array}$ & $0(0)$ \\
\hline $\begin{array}{l}\text { Luminal B, HER2 negative (ER/PR } \\
\text { positive \& Ki } 67>20 \% \text { ) }\end{array}$ & $10(29)$ \\
\hline HER2 positive & $6(17)$ \\
\hline TNBC & $19(54)$ \\
\hline
\end{tabular}


Table 1 (Continued)

\begin{tabular}{|l|l|}
\hline Variable & Number (\%) \\
\hline BRCA mutation status & \\
\hline BRCA 1 or 2 mutation present & $6(17)$ \\
\hline Wild type & $6(17)$ \\
\hline Unknown & $23(66)$ \\
\hline De novo metastatic disease & $12(35)$ \\
\hline Recurrent disease & $23(65)$ \\
\hline $\begin{array}{l}\text { Median number of sites of metastatic } \\
\text { disease }\end{array}$ & $2(\text { range: } 0-6)^{d}$ \\
\hline Visceral crisis & $8(23)$ \\
\hline Yes & $27(77)$ \\
\hline No & 1 (range: $0-5)$ \\
\hline $\begin{array}{l}\text { Median number of lines of prior } \\
\text { therapy in metastatic disease }\end{array}$ & \\
\hline
\end{tabular}

Abbreviations: BRCA, breast cancer; ECOG, Eastern Cooperative Oncology Group; ER, estrogen receptor; PR, progesterone receptor; TNBC, triple-negative breast cancer.

${ }^{\mathrm{a}}$ One male patient was excluded.

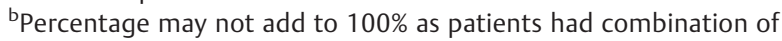
comorbid illness.

'One patient has metaplastic carcinoma and 1 patient had poorly differentiated carcinoma with neuroendocrine features.

${ }^{\mathrm{d}}$ Range starts with 0 as 3 patients had only locally progressive disease.

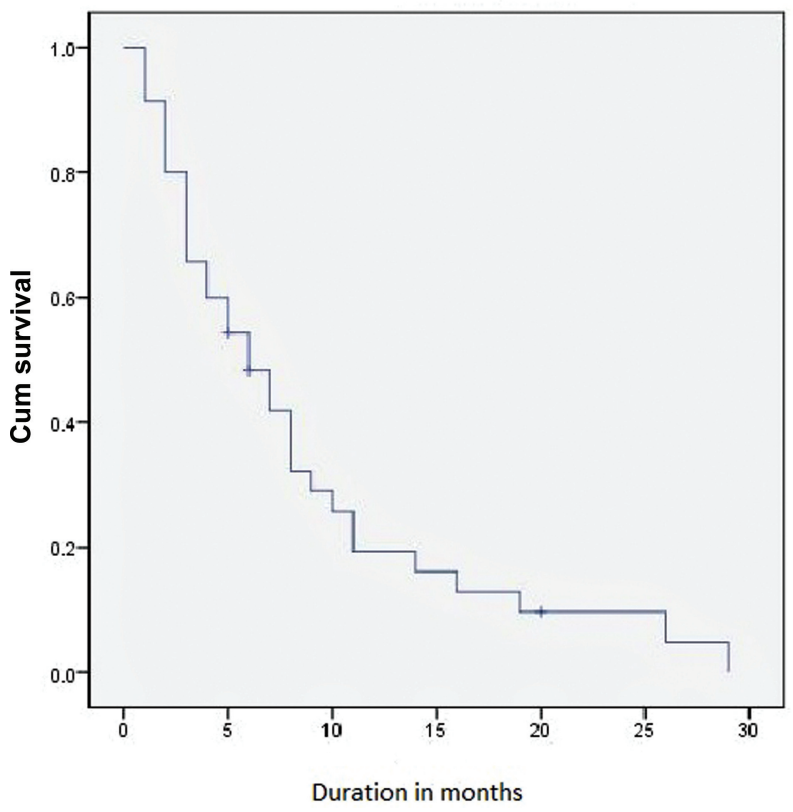

Fig. 1 Kaplan-Meier curve ( $x$-axis: survival in months; $y$-axis: percentage of patients) of 35 patients with advanced breast cancer treated with gemcitabine-carboplatin showing a median progressionfree survival of 6 months (95\% confidence interval: 3.2-5.7 months).

CI: 5.3-10.7 months), respectively. The 1-year PFS and OS were 19 and 34\%, respectively. Univariate analysis was done with factors including age, menopausal status, histology, molecular subtype, BRCA status, number of lines of prior

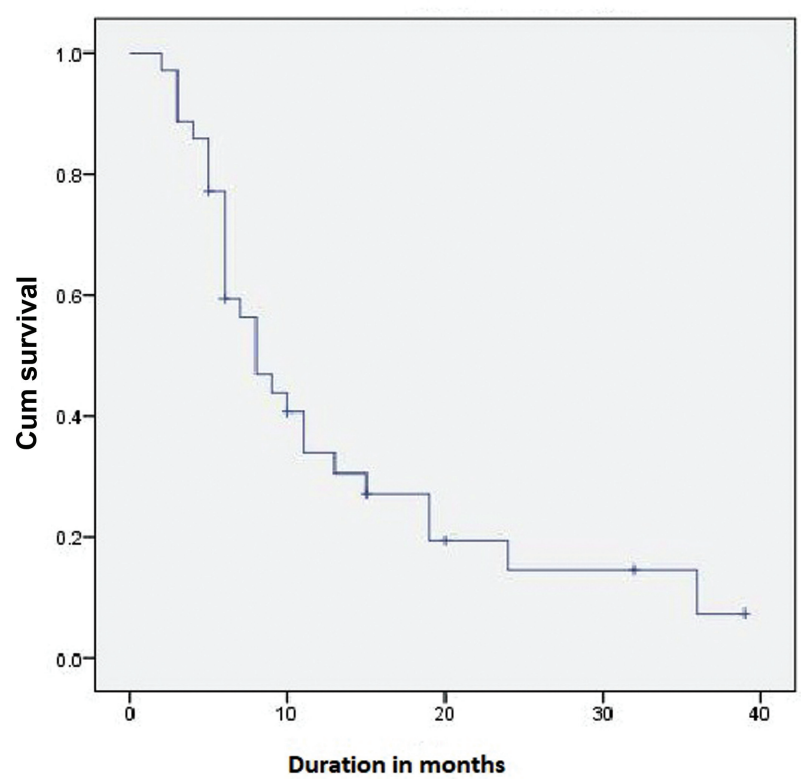

Fig. 2 Kaplan-Meier curve (x-axis: survival in months; $y$-axis: percentage of patients) of 35 patients with advanced breast cancer treated with gemcitabine-carboplatin showing a median overall survival of 8 months ( $95 \%$ confidence interval: 5.3-10.7 months).

therapy, number of sites of metastasis, and number of cycles of GC chemotherapy for correlation with PFS. Univariate analysis showed that patients with infiltrating ductal carcinoma histology and those who received more than 3 cycles of chemotherapy had better PFS ( - Table 2). Multivariate analysis confirmed that patients who had received more than three cycles of chemotherapy had better PFS (hazard ratio: 3.05, 95\% CI: 1.36-6.82, $p=0.007)$.

\section{Discussion}

This study is the largest study from India on PBC in ABC. The study included real-world patients like those in ECOG PS 2 (17\%), HER2 positivity (17\%), and pretreated (maximum 5 lines of prior systemic therapy) ABC who were treated with gemcitabine and carboplatin.

Currently, there is no standard chemotherapy option in patients who progress after exposure to anthracycline, taxane, and capecitabine. The chemotherapy options include ixabepilone, vinorelbine, eribulin, and PBC. We chose GC as it was an affordable treatment option.

Germline BRCA testing was done in 12 patients. Among them, 6 patients (50\%) had BRCA 1 mutation and none had BRCA 2 mutation. The NCCN guidelines recommend BRCA testing for all patients with a family history of breast or ovarian cancer, age less than 45 years, bilateral BRCA, male BRCA, breast and ovarian cancer, and TNBC less than 60 years of age.

Biopsy confirmation of recurrent disease was done only in $37 \%$ due to inaccessible site, patient's unwillingness, and short disease-free survival. All current guidelines including (NCCN), American Society of Medical Oncology, European Society of Medical Oncology, and $\mathrm{ABC}$ recommend repeat biopsy from accessible metastatic setting especially in the 
Table 2 Univariate analysis with correlation with progressionfree survival

\begin{tabular}{|l|l|l|l|}
\hline Variable & HR & Cl (95\%) & -Value \\
\hline Histology & & & \\
\hline $\begin{array}{l}\text { Infiltrating ductal } \\
\text { carcinoma }\end{array}$ & 1.00 & & \\
\hline Others & 2.40 & $1.04-5.67$ & 0.04 \\
\hline Molecular subtype & & & \\
\hline Luminal B & 1.00 & & \\
\hline HER2 enriched & 1.23 & $0.33-4.60$ & 0.75 \\
\hline $\begin{array}{l}\text { Triple negative breast } \\
\text { cancer }\end{array}$ & 1.76 & $0.79-3.92$ & 0.16 \\
\hline $\begin{array}{l}\text { Number of cycles of } \\
\text { chemotherapy }\end{array}$ & 1.00 & & \\
\hline$>3$ cycles & 3.23 & $1.47-7.06$ & 0.03 \\
\hline$\leq 3$ cycles & 1.00 & & \\
\hline $\begin{array}{l}\text { Number of sites of } \\
\text { metastatic disease }\end{array}$ & 0.46 & $0.16-1.35$ & 0.16 \\
\hline$\leq 2$ sites & 0.88 & $0.39-1.99$ & 0.76 \\
\hline$>2$ sites & 0.43 & $0.10-1.78$ & 0.25 \\
\hline $\begin{array}{l}\text { Number of lines of prior } \\
\text { systemic therapy for } \\
\text { metastatic disease }\end{array}$ & & & \\
\hline$\leq 2$ lines & & & \\
\hline$>2$ lines & & & \\
\hline BRCA mutation & & & \\
\hline BRCA positive & & & \\
\hline BRCA wild type & & & \\
\hline
\end{tabular}

Abbreviations: BRCA, breast cancer; $\mathrm{Cl}$, confidence interval; $\mathrm{HR}$, hazard ratio.

first recurrence. Repeat biopsy is useful as it not only confirms the recurrence but also identifies discordance in ER, PR, and HER2 status that can alter systemic therapy. ${ }^{8}$ Studies from All India Institute of Medical Sciences, Delhi and Kidwai, Bengaluru have shown a receptor (ER/PR/HER2) discordance of 10 to $20 \%$ in recurrent BRCA and can be useful in treatment decisions. 9,10

A Cochrane database systematic review $(n=9742)$ showed that combination chemotherapy had improved response and survival but with increased toxicity. ${ }^{11}$ But another Cochrane database systemic review $(n=2317)$ showed no difference in OS in patients receiving combination versus sequential single-agent chemotherapy. ${ }^{12}$ Currently, we do not have studies comparing GC to carboplatin alone in advanced BRCA.

In our study, dose reduction with GC chemotherapy was seen in $74 \%$. A phase 2 study showed that dose reductions with GC occurred in $60 \%$ due to myelosuppression. ${ }^{13}$ Although dose reduction happened in two-thirds of the patients, most patients completed all the six cycles of chemotherapy.
A study from Gujarat Cancer Research Institute in 21 patients with TNBC showed a response rate of $72 \%$ and the survival details were unreported. ${ }^{14}$ There are no further studies on $\mathrm{PBC}$ in $\mathrm{ABC}$ from India. Our study had a lower overall response rate (34\%) as it included pretreated patients with $A B C$. A retrospective study of patients $(n=375)$ with de novo $A B C$ from All India Institute of Medical Sciences, Delhi, showed that hormone-positive subset, good PS (0-1), and oligometastasis had a better outcome. Patients with TNBC and those with liver or brain metastasis had a poor outcome. ${ }^{15}$

A study from Royal Marsden showed that PBC improved response and PFS but not OS in patients with advanced TNBC. ${ }^{16}$ The triple-negative (TNT) randomized controlled trial (RCT) in patients with untreated TNBC, carboplatin, and docetaxel had similar response and survival. But in patients with BRCA mutated TNBC, carboplatin had a better response and survival. ${ }^{17}$ A phase 3 RCT from China showed that patients treated with GC had a better PFS than gemcitabine-paclitaxel in untreated advanced TNBC. ${ }^{18}$ A meta-analysis with three RCTs showed that PBC does not improve PFS in patients with advanced TNBC. ${ }^{19}$ Another meta-analysis of 4,625 patients with $\mathrm{ABC}$ showed that $\mathrm{PBC}$ improved PFS and OS with increased fatigue, hematological, and gastrointestinal toxicity. ${ }^{20}$ The details of the studies with $\mathrm{PBC}$ in $\mathrm{ABC}$ are shown in - Table 3.

In our study, the median PFS and OS were only 6 and 8 months, respectively. This could be due to the inclusion of real-world patients like heavily pretreated subset and HER2positive patients (who could not afford anti-HER2 therapy). The TNBC and BRCA mutant subtype did not correlate with survival possibly because of the small numbers. GC-based regimen could be considered as first-line regimen in patients with BRCA mutant advanced TNBC and as a third-line regimen after anthracycline and taxane in patients with BRCA wild-type advanced TNBC.

Poly ADP ribose polymerase (PARP) inhibitors (olaparib, talazoparib) had shown to improve response and PFS as compared to non-PBC (capecitabine, eribulin, or vinorelbine) in patients with germline BRCA-mutated advanced BRCA. 21,22 However, the addition of PARP inhibitor (iniparib) to GC chemotherapy did not improve survival in patients with advanced TNBC. ${ }^{23}$

Immunotherapy (atezolizumab) with nab-paclitaxel had shown to improve survival as compared to nab-paclitaxel alone in patients with untreated advanced TNBC, especially the PD-L1-positive subset. ${ }^{24}$ Pembrolizumab with chemotherapy (nab-paclitaxel, paclitaxel, gemcitabine + carboplatin) improved PFS as compared to chemotherapy alone in patients with PD-L1-positive (combined positive score $\geq 10$ ) untreated advanced TNBC. Sacituzumab govitecan-hziy is an antibody-drug conjugate that targets the human trophoblast cell-surface antigen 2 (Trop-2) with SN-38 had shown durable responses in patients with heavily pretreated advanced TNBC. ${ }^{20}$

The multivariate analysis showed that patients who received more than three cycles of chemotherapy had an improved PFS. None of the other studies of PBC in ABC had shown a similar correlation. The strength includes the first 
Platinum-Based Chemotherapy in Advanced Breast Cancer Vaikundaraja et al.

Table 3 Studies on platinum-based chemotherapy in advanced breast cancer

\begin{tabular}{|c|c|c|c|c|c|c|}
\hline Study & $\begin{array}{l}\text { Inclusion } \\
\text { criteria }\end{array}$ & Sample size & Design & Response (\%) & PFS (mo) & OS (mo) \\
\hline Our study & $\mathrm{ABC}$ & 35 & Retrospective & 34 & $6 \mathrm{mo}$ & $8 \mathrm{mo}$ \\
\hline Maka et $\mathrm{al}^{14}$ & TNBC & 21 & Retrospective & 72 & - & - \\
\hline Sirohi et al, UK ${ }^{9}$ & TNBC & 155 & Retrospective & 41 & $6 \mathrm{mo}$ & $11 \mathrm{mo}$ \\
\hline Tutt et al, TNT trial ${ }^{10}$ & TNBC & 766 & $\begin{array}{l}\text { Phase } 3, \mathrm{RCT}, \\
\text { carboplatin } \\
\text { versus docetaxel }\end{array}$ & $\begin{array}{l}31 \text { versus } \\
34 \%\end{array}$ & $\begin{array}{l}3.1 \mathrm{mo} \text { versus } \\
4.4 \mathrm{mo}\end{array}$ & $\begin{array}{l}12.8 \text { mo versus } \\
12 \mathrm{mo}\end{array}$ \\
\hline Hu et al. China ${ }^{11}$ & TNBC & 240 & $\begin{array}{l}\text { Phase } 3, \mathrm{RCT} \text {, } \\
\text { gemcitabine } \\
\text { cisplatin versus } \\
\text { gemcitabine paclitaxel }\end{array}$ & 65 versus $49 \%$ & $\begin{array}{l}7.7 \text { mo versus } \\
6.4 \text { mo }\end{array}$ & Immature \\
\hline
\end{tabular}

Abbreviations: ABC, advanced breast cancer; OS, overall survival; PFS, progression-free survival; RCT, randomized controlled trial; TNBC, triplenegative breast cancer.

study with the largest sample size from India on real-world outcomes with $\mathrm{PBC}$ in $\mathrm{ABC}$. The limitations include retrospective design, lack of biopsy confirmation of recurrence (63\%), and unknown BRCA status (66\%). Further prospective randomized studies are warranted to assess the optimal regimen in patients with $\mathrm{TNBC}$.

\section{Conclusion}

This study is the largest study from India on PBC in ABC representing the real-world outcome. Patients with ECOG PS 2, HER2 positivity, and pretreated $A B C$ were included in this analysis. GC was an active and well-tolerated regimen in advanced BRCA regardless of the receptor status.

\section{Presentation}

This study has not been presented in any meeting.

\section{Registration Number}

Not applicable as it is not a clinical trial.

\section{Authors' Contribution}

Conception (Indhuja Muthiah Vaikundaraja, Manikandan Dhanushkodi)/acquisition (Indhuja Muthiah Vaikundaraja, Manikandan Dhanushkodi)/analysis (Indhuja Muthiah Vaikundaraja, Manikandan Dhanushkodi, Venkatraman Radhakrishnan, Jayachandran Perumal Kalaiarasi, Nikita Mehra, Arun Kumar Rajan, Gangothri Selvarajan, Siva Sree Kesana, Balasubramanian Ananthi, Priya Iyer, Manjula Rao, Arvind Krishnamurthy, Sridevi Velusamy, Rama Ranganathan, Tenali Gnana Sagar). All authors made substantial contribution toward drafting and final approval and agreed to be accountable on all aspects of the manuscript.

\section{Source of Funding}

Nil.

\section{Conflict of Interest}

Nil.

\section{Acknowledgement}

None.

\section{References}

1 Loibl S, O'Shaughnessy J, Untch M, et al. Addition of the PARP inhibitor veliparib plus carboplatin or carboplatin alone to standard neoadjuvant chemotherapy in triple-negative breast cancer (BrighTNess): a randomised, phase 3 trial. Lancet Oncol 2018;19 (04):497-509

2 Slamon D, Eiermann W, Robert N, et al; Breast Cancer International Research Group. Adjuvant trastuzumab in HER2-positive breast cancer. N Engl J Med 2011;365(14):1273-1283

3 Shamseddine AI, Farhat FS. Platinum-based compounds for the treatment of metastatic breast cancer. Chemotherapy 2011;57 (06):468-487

4 Decatris MP, Sundar S, O'Byrne KJ. Platinum-based chemotherapy in metastatic breast cancer: current status. Cancer Treat Rev 2004;30(01):53-81

5 breast_risk.pdf, https://www.nccn.org/professionals/physician_ gls/pdf/breast_risk.pdf. Accessed July 17, 2021

6 Eisenhauer EA, Therasse P, Bogaerts J, et al. New response evaluation criteria in solid tumours: revised RECIST guideline (version 1.1). Eur J Cancer 2009;45(02):228-247

7 Common Terminology Criteria for Adverse Events (CTCAE). 79 (2009), https://evs.nci.nih.gov/ftp1/CTCAE/CTCAE_4.03/Archive/ CTCAE_4.0_2009-05-29_QuickReference_8.5x11.pdf. Accessed July 17, 2021

8 Simmons C, Miller N, Geddie W, et al. Does confirmatory tumor biopsy alter the management of breast cancer patients with distant metastases? Ann Oncol 2009;20(09):1499-1504

9 Sharma M, Gogia A, Deo SSV, Mathur S. Role of rebiopsy in metastatic breast cancer at progression. Curr Probl Cancer 2019;43(05):438-442

10 Anand A, Jacob LA, Lakshmaiah KC, et al. Repeat biopsy a must in recurrent breast cancer: a study from tertiary cancer centre in India. Ann Oncol 2018;29:ix16-ix17

11 Carrick S, Parker S, Thornton CE, Ghersi D, Simes J, Wilcken N. Single agent versus combination chemotherapy for metastatic breast cancer. Cochrane Database Syst Rev 2009;2009(02): CD003372 
12 Dear RF, McGeechan K, Jenkins MC, Barratt A, Tattersall MH, Wilcken N. Combination versus sequential single agent chemotherapy for metastatic breast cancer. Cochrane Database Syst Rev 2013;CD008792(12):CD008792. Doi: 10.1002/ 14651858.CD008792.pub2

13 Maisano R, Zavettieri M, Azzarello D, et al. Carboplatin and gemcitabine combination in metastatic triple-negative anthracycline- and taxane-pretreated breast cancer patients: a phase II study. J Chemother 2011;23(01):40-43

14 Maka VV, Panchal H, Shukla SN, Talati SSDepartment of Medical Oncology Gujarat Cancer and Research Institute Ahmedabad Gujarat India. Platinum-based chemotherapy in metastatic triple negative breast cancer: experience of a tertiary referral centre in India. Gulf J Oncolog 2015;1(17):52-57

15 Gogia A, Deo SVS, Sharma D, et al. Clinicopathologic characteristics and treatment outcomes of patients with up-front metastatic breast cancer: single-center experience in India. J Glob Oncol 2019;5:1-9

16 Sirohi B, Arnedos M, Popat S, et al. Platinum-based chemotherapy in triple-negative breast cancer. Ann Oncol 2008;19(11): 1847-1852

17 Tutt A, Tovey H, Cheang MCU, et al. A randomised phase III trial of carboplatin compared with docetaxel in BRCA1/2 mutated and pre-specified triple negative breast cancer "BRCAness" subgroups: the TNT trial. Nat Med 2018;24:628-637
$18 \mathrm{Hu} \mathrm{X-C,} \mathrm{Zhang} \mathrm{J,} \mathrm{Xu} \mathrm{BH,} \mathrm{et} \mathrm{al.} \mathrm{Cisplatin} \mathrm{plus} \mathrm{gemcitabine} \mathrm{versus}$ paclitaxel plus gemcitabine as first-line therapy for metastatic triple-negative breast cancer (CBCSG006): a randomised, openlabel, multicentre, phase 3 trial. Lancet Oncol 2015;16(04):436-446

19 Pandy JGP, Balolong-Garcia JC, Cruz-Ordinario MVB, Que FVF. Triple negative breast cancer and platinum-based systemic treatment: a meta-analysis and systematic review. BMC Cancer 2019; 19(01):1065

20 Petrelli F, Barni S, Bregni G, de Braud F, Di Cosimo S. Platinum salts in advanced breast cancer: a systematic review and meta-analysis of randomized clinical trials. Breast Cancer Res Treat 2016;160 (03):425-437

21 Robson M, Im SA, Senkus E, et al. Olaparib for metastatic breast cancer in patients with a germline BRCA mutation. $\mathrm{N}$ Engl J Med 2017;377(06):523-533

22 Litton JK, Rugo HS, Ettl J, et al. Talazoparib in patients with advanced breast cancer and a germline BRCA mutation. $\mathrm{N}$ Engl J Med 2018;379(08):753-763

23 O'Shaughnessy J, Schwartzberg L, Danso MA, et al. Phase III study of iniparib plus gemcitabine and carboplatin versus gemcitabine and carboplatin in patients with metastatic triple-negative breast cancer. J Clin Oncol 2014;32(34):3840-3847

24 Schmid P, Adams S, Rugo HS, et al; IMpassion130 Trial Investigators. Atezolizumab and nab-paclitaxel in advanced triple-negative breast cancer. N Engl J Med 2018;379(22):2108-2121 